\section{(6) OPEN ACCESS}

\title{
Joint UK societies' 2014 consensus statement on renal denervation for resistant hypertension
}

\author{
Melvin D Lobo, ${ }^{1,2,3}$ Mark A de Belder, 4,5,6 Trevor Cleveland, ${ }^{7,8}$ David Collier, 1,2 \\ Indranil Dasgupta, ${ }^{9,10}$ John Deanfield, ${ }^{6,11}$ Vikas Kapil, ${ }^{1,2,3}$ Charles Knight, $^{3,4}$ \\ Matthew Matson, 7,2 Jonathan Moss, 7,12 Julian F R Paton, ${ }^{1,13}$ Neil Poulter, 1,14 \\ lain Simpson, ${ }^{4,15}$ Bryan Williams, ${ }^{1,16}$ Mark J Caulfield ${ }^{1,2,3}$
}

For numbered affiliations see end of article.

\section{Correspondence to}

Dr Melvin D Lobo, Centre for Clinical Pharmacology, William Harvey Heart Centre, Barts and the London School of Medicine and Dentistry, Queen Mary University of London, Charterhouse Square, London EC1M 6BQ, UK

m.d.lobo@qmul.ac.uk

Accepted 21 October 2014 Published Online First 27 November 2014

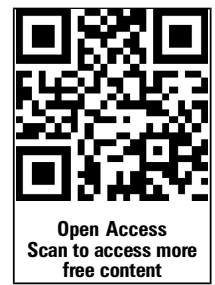

\section{CrossMark}

To cite: Lobo MD, de Belder MA, Cleveland T, et al. Heart 2015;101: 10-16.

\section{ABSTRACT}

Resistant hypertension continues to pose a major challenge to clinicians worldwide and has serious implications for patients who are at increased risk of cardiovascular morbidity and mortality with this diagnosis. Pharmacological therapy for resistant hypertension follows guidelines-based regimens although there is surprisingly scant evidence for beneficial outcomes using additional drug treatment after three antihypertensives have failed to achieve target blood pressure. Recently there has been considerable interest in the use of endoluminal renal denervation as an interventional technique to achieve renal nerve ablation and lower blood pressure. Although initial clinical trials of renal denervation in patients with resistant hypertension demonstrated encouraging office blood pressure reduction, a large randomised control trial (Symplicity HTN-3) with a sham-control limb, failed to meet its primary efficacy end point. The trial however was subject to a number of flaws which must be taken into consideration in interpreting the final results. Moreover a substantial body of evidence from nonrandomised smaller trials does suggest that renal denervation may have an important role in the management of hypertension and other disease states characterised by overactivation of the sympathetic nervous system. The Joint UK Societies does not recommend the use of renal denervation for treatment of resistant hypertension in routine clinical practice but remains committed to supporting research activity in this field. A number of research strategies are identified and much that can be improved upon to ensure better design and conduct of future randomised studies.

\section{SCOPE OF THE CONSENSUS STATEMENT}

Resistant hypertension (RHTN) is increasingly recognised as an important subset of uncontrolled hypertension that carries substantial additional risk for cardiovascular disease. ${ }^{1}{ }^{2}$ Wide-ranging prevalence for RHTN has been reported which varies depending on which cohorts have been examined. However, it seems likely that the overall prevalence is around $8-10 \%$ of all patients with hypertension and that improved treatment of this group would lead to considerable reduction in cardiovascular morbidity and mortality making it a high priority hypertension subset. ${ }^{3} 4$

Renal denervation (RDN) therapy has recently become available as a treatment for proven RHTN, albeit with a clinical effectiveness evidence base limited to studies lacking blinded end points or sham controls and mostly with small numbers of patients. $^{5-7}$ Following the announcement by Medtronic on 9 January 2014 that the Symplicity hypertension (HTN)-3 trial had failed to meet its primary efficacy end point, the Joint UK Societies released an interim statement recommending a temporary moratorium on RDN procedures undertaken as a standard of care in the UK while awaiting formal reporting and peer-reviewed publication of the study results. ${ }^{8}$ This updated statement was prepared following the recent publication of the Symplicity HTN-3 study-a prospective, singleblind, randomised, sham-controlled trial that took place in the USA. ${ }^{10}$ In this document we consider the RDN landscape that set the stage for the Symplicity HTN-3 study and thereafter review the study design and results. A number of limitations affecting the execution of the study are now apparent that provide important lessons for future studies of RDN. Importantly, given the conflicting evidence regarding the role of $\mathrm{RDN}$, it is too early to use the Symplicity HTN-3 outcome as a rationale to abandon this novel therapeutic development. Here we also address critical issues that must be overcome if RDN is to progress as a therapy for RHTN or other forms of hypertension.

\section{SYMPLICITY HTN-3 BACKGROUND}

The Symplicity HTN-3 study was conceived and designed as a regulatory study for US approval of RDN therapy as part of an ongoing multistage global clinical evaluation programme for radiofrequency (RF) RDN initiated by Medtronic. ${ }^{11}$ The study design allowed the investigators to address numerous concerns that had arisen in light of the initial studies reporting RDN as an efficacious and safe therapy for RHTN (see table 1).

Principal among these concerns were the fact that existing studies had failed to include blinded end points and, in particular, there was no mandated use of ambulatory blood pressure monitoring (ABPM) as a means to diagnose RHTN and to monitor response to the therapy. Furthermore, although Symplicity HTN-2 was a randomised controlled study, there was no sham control procedure which has been recorded as important in the proper evaluation of novel interventional procedures. $^{29} 30$ Despite being a novel interventional procedure, there have been very few adverse reports pertaining to safety of the procedure, or long-term harmful sequelae although this may simply reflect numbers of procedures performed to 
Table 1 Criticisms of clinical renal denervation (RDN) data to date

\begin{tabular}{|c|c|c|}
\hline Criticism & Problem & Potential solutions \\
\hline Trial design & $\begin{array}{l}\text { Non-blinded design } \\
\text { Lack of sham control }\end{array}$ & $\begin{array}{l}\text { Double-blind RDN versus sham procedure with best medical } \\
\text { therapy }{ }^{10}\end{array}$ \\
\hline \multirow[t]{5}{*}{$\begin{array}{l}\text { Patient selection and } \\
\text { management }\end{array}$} & No per protocol exclusion of secondary causes of hypertension & $\begin{array}{l}\text { Mandatory per protocol exclusion of secondary causes of } \\
\text { hypertension }\end{array}$ \\
\hline & Ensure adherence to medication & $\begin{array}{l}\text { Plasma/urine assay of medications/metabolites } \pm \text { directly observed } \\
\text { therapy before qualifying BP measurement }\end{array}$ \\
\hline & Per protocol managed lifestyle changes & Optimal 24-h urinary sodium excretion \\
\hline & Non-optimised antihypertensive medications & $\begin{array}{l}\text { Guidelines-based treatment regimens with add-on spironolactone } \\
\text { and/or } \alpha \text {-blockade }\end{array}$ \\
\hline & Heterogeneity of patient suitability rates between RDN centres ${ }^{12} 13$ & Referral to hypertension specialist centres \\
\hline Ambulatory BP & $\begin{array}{l}\text { Unnecessary inclusion of pseudoresistant patients with hypertension }{ }^{5} 6 \\
\text { and potential overestimation of effect on office BP } \\
\text { Less reduction in ambulatory BP parameters compared with office BP }{ }^{14}\end{array}$ & Use of ambulatory BP as entry and outcome criteria ${ }^{15} 16$ \\
\hline $\begin{array}{l}\text { Human renal nerve } \\
\text { anatomy uncertain }\end{array}$ & Optimal sites for RDN yet to be defined & Targeting of renal nerves depends also on energy modality used ${ }^{18}$ \\
\hline \multirow[t]{4}{*}{ Renovascular safety } & $\begin{array}{l}\text { Incomplete characterisation of renovascular injury periprocedurally and in } \\
\text { the long term }{ }^{17}\end{array}$ & Further use of optical coherence tomography ${ }^{17}$ \\
\hline & Reporting of only $>60 \%$ stenoses $^{6}$ & Postprocedure CT angiography or magnetic resonance \\
\hline & No histological safety data from humans & angiography (MRA) at $6-12$ months $^{19}$ \\
\hline & $\begin{array}{l}\text { Requirement for concurrent, periprocedural antiplatelet therapy to be } \\
\text { determined }^{17}\end{array}$ & $\begin{array}{l}\text { Further studies needed-may vary with energy modality used for } \\
\text { RDN }\end{array}$ \\
\hline \multirow[t]{2}{*}{ Predictors of response } & Only baseline, office SBP reliably predicts response across studies 5620 & $\begin{array}{l}\text { Autonomic function testing (where available) to be included in } \\
\text { clinical studies and registries }{ }^{5} 2223\end{array}$ \\
\hline & Inability to distinguish between procedural failure or non-response & Research into ontable assessment of efficacy of RDN ${ }^{24} 25$ \\
\hline $\begin{array}{l}\text { Heterogeneity of BP } \\
\text { response }\end{array}$ & $\begin{array}{l}\text { Wide variation in response to RDN raises questions about role of renal } \\
\text { nerves in hypertension }{ }^{21}\end{array}$ & $\begin{array}{l}\text { Research focusing on renal nerve physiology in hypertension and } \\
\text { role of RDN } 2627\end{array}$ \\
\hline \multirow{2}{*}{$\begin{array}{l}\text { Durability of response and } \\
\text { end points }\end{array}$} & 6-month office BP as primary end point ${ }^{5620}$ & Major adverse events as primary end points \\
\hline & No data greater than 3 years post procedure published ${ }^{28}$ & Studies and registries to extend to several years \\
\hline
\end{tabular}

BP, blood pressure; SBP, systolic BP.

date and lack of true long-term follow-up. Case reports of renal artery stenosis following denervation are a reminder of the importance of long-term scrutiny for renovascular disorder following RDN and careful surveillance of biochemical renal function. $^{31} 32$

Other concerns over published RDN data sets included lack of specialist management of patients with RHTN (diagnosis and treatment, adequacy of per-protocol exclusion of secondary HTN), and that adherence to antihypertensive medication prior to enrolment and during the course of studies had not been assessed. ${ }^{33}{ }^{34}$ Concomitantly, hypertension specialists in a number of European centres had also started to investigate the utility of RDN in patients with RHTN and have reported that the number of patients suitable for RDN (after specialist assessment and medication adjustment) would be very limited. ${ }^{12} 3536$ Furthermore the high responder rates of $80 \%$ or more patients exhibiting office systolic blood pressure (SBP) reduction of $>10 \mathrm{~mm} \mathrm{Hg}$ in earlier trials were not replicable in a number of smaller studies which showed less striking blood pressure (BP) lowering and substantial heterogeneity of $\mathrm{BP}$ responses to RDN. ${ }^{37-39}$

\section{SYMPLICITY HTN-3 STUDY DESIGN AND RESULTS}

The Symplicity HTN-3 study was a prospective, single-blind, randomised, sham-controlled trial in which patients with severe RHTN (office BP >160 $\mathrm{mm} \mathrm{Hg}$ and 24-h mean SBP >135 mm Hg) were randomly assigned in a 2:1 ratio to undergo RDN or a sham procedure. ${ }^{11}$ Before randomisation, patients were intended to be receiving a stable antihypertensive regimen involving maximally tolerated doses of at least three drugs, including a diuretic. The primary efficacy end point was the change in office SBP at 6 months; a secondary efficacy end point was the change in mean 24-h ambulatory SBP. In total 535 subjects were randomised of whom 364 received RDN therapy and 171 had a sham procedure. The investigators ensured adequate blinding of study participants such that they were unaware whether they had received RDN therapy or sham control (renal angiogram) and $\mathrm{BP}$ assessors were blinded to the study group assignments. Although the primary safety end point was met, with a major adverse event rate of only $1.4 \%$ (set against an objective performance goal of $<9.8 \%$ ), the study failed to meet its primary and secondary efficacy end points with no statistically significant difference in either office or ABPM BP lowering between the RDN treatment and sham control arms (figure 1). Substantial variation in BP responses was noted in both study groups and subgroup analyses indicated that RDN therapy might work better in patients of non-African-American ethnicity, patients below the age of 65 years and those with preserved renal function (estimated glomerular filtration rate $>60 \mathrm{~mL} / \mathrm{min}$ ). ${ }^{10}$

\section{SYMPLICITY HTN-3: STUDY LIMITATIONS AND LESSONS FOR FUTURE TRIALS OF RDN}

The Symplicity HTN-3 study improved upon Symplicity HTN-1 and HTN-2 in having a blinded secondary end point (ABPM) and a sham control group. However, following publication of the results and presentation in international meetings, a number of findings have come to light that indicate that there are important lessons to be learnt about the optimal design and execution of such studies.

\section{Medications stability}

The study design mandated each enrolled patient was on a maximum tolerated dose or maximum Food and Drug Administration (FDA)-approved dose of at least three antihypertensive agents from different classes, for at least 2 weeks prior 

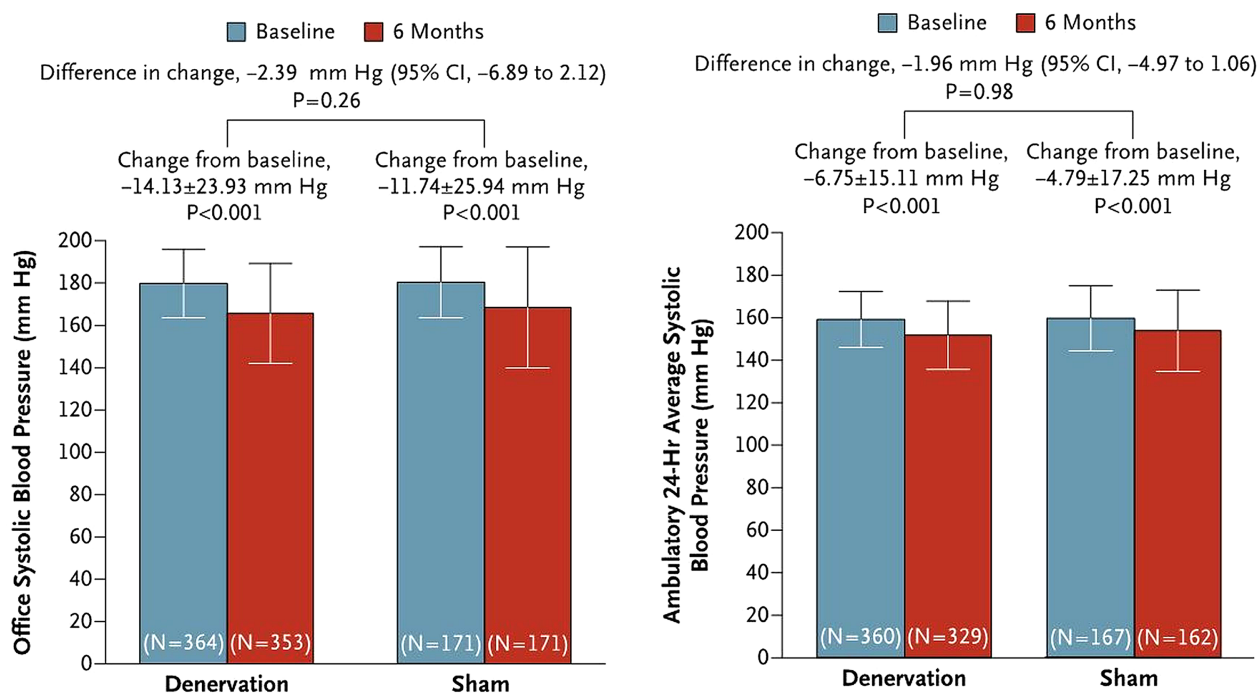

Figure 1 Symplicity HTN-3 results of primary and secondary efficacy end points.

to enrolment. Although there was an emphasis on maintaining a constant therapeutic regimen throughout the study, as many as $20 \%$ of patients were not on stable medications within 6 weeks of inclusion. ${ }^{40}$ Given that attainment of full effect of diuretics (including aldosterone antagonists) is known to take up to 8 weeks, ${ }^{41}$ it is quite possible that some of the BP changes in both study limbs were due to late effects of the enrolment medication regimen.

There were also substantial differences in use of aldosterone antagonists $(22.5 / 28.7 \%)$ and vasodilators (36.8/45\%) between the $\mathrm{RDN} / \mathrm{sham}$ limbs at baseline, respectively, and a preponderance of African-Americans, who are more likely to respond to these drug classes, in the sham group (29.2\% sham vs $24.8 \%$ RDN). Indeed African-American patients demonstrated a striking SBP reduction of $17.8 \mathrm{~mm} \mathrm{Hg}$ in the sham arm versus $15.5 \mathrm{~mm} \mathrm{Hg}$ in the RDN limb.

Approximately $40 \%$ of patients in both arms required medications changes during the study which is unusual. ${ }^{40}$ The exact reasons for and the disposition of the medication changes are yet to be clarified. It is noteworthy that there were eight points of investigator/subject contact during the study with close scrutiny of medications and BP at every point. It is possible that medication compliance was artificially enhanced in this study (the Hawthorne effect). Of note, although patients were asked to maintain a medication diary, adherence to antihypertensive medication was not formally tested by directly observed therapy or by urine antihypertensive drug assay in this study. It is also unfortunate that longterm follow-up of the sham control population is already confounded by high cross-over to active therapy with RDN which will negatively impact on the opportunity to determine if the sham treatment alone had long-term implications for BP control.

\section{RDN procedures}

Attention has already focused on the large number of sites in Symplicity HTN-3 with 111 interventionists who performed at least one RDN procedure (34\% did only a single procedure) and with only 26 operators undertaking more than five procedures. ${ }^{42}$ Although procedures were proctored (mostly by nonclinical staff), this does not imply that optimal denervation was achieved.

In fact in this study the mean total number of ablation attempts was $11.2 \pm 2.8$ per patient with a mean of $9.2 \pm 2.0$ per protocol $120 \mathrm{~s}$ ablations. In the Global Symplicity Registry (GSR), ambulatory SBP reduced by $10.3 \mathrm{~mm} \mathrm{Hg}$ (in patients with office BP $>160 \mathrm{~mm} \mathrm{Hg}$ and ambulatory BP $>135 \mathrm{~mm} \mathrm{Hg}$ ) compared with a reduction in ambulatory SBP of only $6.8 \mathrm{~mm} \mathrm{Hg}$ in the RDN group and $4.8 \mathrm{~mm} \mathrm{Hg}$ in the sham group in Symplicity HTN $-3 .{ }^{43}$ In the GSR the mean number of bilateral ablations was $13.5 \pm 4.1$, and the mean number of $120 \mathrm{~s}$ bilateral ablations was $11.3 \pm 3.4$. In HTN-3 it was shown that with an increasing number of RF ablations there was a greater reduction in BP; in 40 patients who underwent RDN who had more than 13 total ablation attempts there was a $10.3 \mathrm{~mm} \mathrm{Hg}$ reduction in ambulatory SBP, matching the effect size in the GSR. ${ }^{40}$

In Symplicity HTN-3 only a small proportion of patients had per-protocol RF ablation in all four quadrants of both renal arteries. ${ }^{40}$ Disappointingly, but not surprisingly, matched cohort analysis has indicated that delivery of ablations in all four quadrants of the renal artery was also associated consistently with the greatest reductions in office, home and ambulatory SBP $(-24.3,-9.0$ and $-10.3 \mathrm{~mm} \mathrm{Hg}$, respectively) but this only applied in 19 patients out of 364 patients undergoing RDN. ${ }^{40}$

\section{EVIDENCE THAT SUGGESTS RDN MAY BE BENEFICIAL FOR RHTN}

Data from numerous animal models have previously suggested an important role for the renal sympathetic nervous system (SNS) in the initiation and perpetuation of hypertension. ${ }^{44}$ In addition, a number of human studies had demonstrated the importance of renal nerve signalling in hypertension prior to the publication of the Symplicity HTN-1 and HTN-2 studies. These data have been reviewed extensively elsewhere. ${ }^{45}$ Data from a number of smaller studies have indicated efficacy for $\mathrm{RDN}$ in BP lowering and improving other aspects of cardiovascular function and merit consideration as follows.

\section{Improvement in ABPM parameters}

While Symplicity HTN-1 and HTN-2 provided data for efficacy and safety of RDN, the lack of ABPM in either inclusion criteria or monitoring of $\mathrm{BP}$ in response to RDN has been criticised. However, non-randomised data supporting sizeable effects of RDN on office and ABPM parameters have now been published in a study of 346 patients with true RHTN $(n=303)$ and pseudoresistant HTN $(\mathrm{n}=43) .{ }^{14}$ Early and sustained significant reductions in office SBP and diastolic blood pressure (DBP) were shown at 3 months, 6 months and 12 months follow-up (office SBP: -21.5/ 
-23.7/-27.3 mm Hg, office DBP: $\quad-8.9 /-9.5 /-11.7 \mathrm{~mm} \mathrm{Hg}$ ), respectively. There was a significant reduction with $\mathrm{RDN}$ in $24 \mathrm{~h}$ SBP $(-10.1 /-10.2 /-11.7 \mathrm{~mm} \mathrm{Hg}$, ) and diastolic blood pressure (DBP) $(-4.8 /-4.9 /-7.4 \mathrm{~mm} \mathrm{Hg})$ at 3 months, 6 months and 12 months, respectively, as well as reduction in BP variability in those patients with true RHTN. In patients with pseudoresistant hypertension there was no effect on ABPM post denervation arguing strongly against a sham effect. The GSR, presented at the American College of Cardiology meeting (March 2014), demonstrated a reduction of $10.3 \mathrm{~mm} \mathrm{Hg}$ in mean $24 \mathrm{~h} \mathrm{SBP}$ in 52 patients with treatment-RHTN taking three or more antihypertensives at maximally tolerated doses with an office BP $>160 \mathrm{~mm} \mathrm{Hg} .{ }^{43}$

\section{RDN enables regression of LV hypertrophy}

Reduction in LV hypertrophy and improvement in cardiac function has been demonstrated in patients with RHTN following $\mathrm{RDN}^{46}$ Intriguingly it has been proposed that improvement in cardiac function and LV hypertrophy regression was independent of the magnitude of BP reduction, suggesting suppression of neurohumoural mechanisms. It must be noted however that this was a prospective, non-randomised, open-label unipolar RF denervation single-centre study in a small number of patients without sham control. More recently catheter based RDN was demonstrated to significantly reduce BP and LV mass and improve EF in patients with RHTN using cardiac MRI. ${ }^{47}$ Once again this prospective multicentre study of only 72 patients was non-randomised and with open-label use of RDN. Importantly, however, the magnitude of LV mass reduction seen was less than that noted in echocardiographic studies of RDN but still comparable with that seen in patients with hypertension treated with pharmacotherapy. ${ }^{48}$ Although a profound placebo effect or greater compliance with medication might have influenced results, to some extent the reduction in LV mass occurred independently of BP reduction which raises the tantalising prospect that downregulation of central cardiac (but not vasomotor) sympathetic outflow resulting from RDN may have a direct role to play in modulating hypertensive heart disease. The potential of RDN as a treatment for heart failure warrants further study.

\section{Other possible cardiovascular benefits of RDN}

RDN reduces heart rate in humans and may have beneficial effects in cardiac rhythm disturbance including reduction in burden of atrial fibrillation and possibly ventricular arrhythmias as well. ${ }^{49} 50$ RDN was shown to reduce arterial stiffness and central haemodynamics which are important prognostic markers and this too merits further investigation. ${ }^{51}$ In two small studies, investigators have shown that RDN improves health-related quality of life and that this improvement was not necessarily related to the magnitude of BP reduction. ${ }^{52} 53$

\section{CURRENT STATE OF RDN THERAPY IN THE UK}

When RDN therapy first became available as a treatment for RHTN, there was rapid uptake of the procedure in a number of European Union territories where a Conformité Européene mark had been established for various competing technologies and this led to over $10000 \mathrm{RDN}$ procedures being undertaken worldwide with regrettably little in the way of data capture with the exception of several investigators who have been pioneers in the field. In contrast, UK uptake has been much slower with only a handful of centres offering the procedure with responder rates that have been markedly heterogeneous and less encouraging on the whole. 225455

At one point in 2013 there were more than 60 companies with technologies in development for RDN including first and second generation RF ablation catheters, ultrasound catheters, radiotherapy catheters, cryotherapy and chemical ablation technologies. ${ }^{18}$ Following the Symplicity HTN-3 announcement a number of companies have announced their withdrawal from the field of device therapy for hypertension including such large entities as Covidien. However, several of the major devices manufactures including Boston Scientific, Medtronic and St Jude Medical, having suspended clinical trial activity within preexisting programmes, have announced their intention to commit to the field of renal sympathectomy. They are using the outputs from Symplicity HTN-3 as an opportunity to improve design of their future clinical trials.

\section{THE JOINT UK SOCIETIES UPDATED PERSPECTIVE}

After reviewing the evidence from the Symplicity HTN-1 and HTN-2 studies, the Joint UK Societies produced guidance for the use of RDN in the UK in 2011 which was summarised in an electronically published summary consensus statement. ${ }^{56}$ The National Institute for Health and Care Excellence subsequently produced interim guidance for RDN that was very much in line with our initial guidance. ${ }^{57}$ In order to protect patients from overenthusiastic and/or inappropriate application of the procedure, it was mandated that patients only be treated with RDN in the context of multidisciplinary assessment in centres of excellence with Hypertension Specialists leading on case management. The procedure, which would be costly for the UK's National Health Service, was to be funded by a novel process of 'Commissioning Through Evaluation' designed to ensure capture of data from all procedures in a national registry, which would serve as a clinical and academic resource. ${ }^{58}$ Subsequently other expert group statements have also been published from the European Society of Hypertension, European Society of Cardiology, Cardiovascular and Interventional Radiology Society of Europe and an International expert Consensus Statement all supporting the use of RDN therapy as a treatment option for RHTN where routine measures to control BP have failed. $^{59-62}$

Following close upon the heels of the Medtronic Symplicity HTN-3 press announcement, the Joint UK Societies produced an interim statement calling for a temporary moratorium on UK use of RDN therapy in anticipation of the formal publication and presentation of the data. ${ }^{9}$ Even allowing for debate over the interpretation of the outcomes of the Symplicity HTN-3 study, there is still a lack of evidence to support the routine use of RDN as a standard of care in RHTN. Hence, we recommend the current moratorium on use of this procedure in the UK remains in place until such time as there is Level 1 evidence in favour of use of RDN. This view is in line with the published evidence and is supported by a recent meta-analysis suggesting that more large-scale randomised controlled trials in RDN are needed before this treatment should be considered in routine clinical practice. ${ }^{63}$

Importantly, the Joint UK Societies recognise that a substantial amount of (Level II or lesser) evidence does suggest clinical utility for RDN therapy in some patients and thus we feel that the therapy should not be abandoned in light of the Symplicity HTN-3 study result. Indeed, this study has continued to disseminate outputs that are proving to be helpful in our learning of how better to manage future studies of RDN. It will be essential for device manufacturers, multidisciplinary clinicians and researchers to collaborate closely to effectively define the path for future studies. Key learning points from the Symplicity HTN-3 study are summarised in table 2. 
The UK remains committed to leading, supporting and participating in well-designed randomised controlled studies to assess the future role of RDN in RHTN. As such the moratorium does not apply to clinical trials of RDN therapy. It is important that alternative energy modalities, such as ultrasound and chemical ablation technologies should be investigated along with second and third generation RF catheters in appropriately designed clinical studies with blinded end points to include ABPM. In RHTN it is vital that careful evaluation of drug adherence is included as a prerequisite to study entry unless severe medication intolerance has been diagnosed. Recently mass spectrometry drug measurement in urine has demonstrated that many patients are not adherent with their therapy. ${ }^{64}$ The application of similar measures in future studies will robustly confirm resistance and allow us to detect non-concordance. It is also important that patients should not be enrolled in studies within 8 weeks of the last change in treatment.

\section{CRITICAL AREAS TO ADDRESS TO DETERMINE THE ROLE OF RDN AS A THERAPY FOR RHTN}

The key areas that future research in RDN must address are summarised in table 1 . It is remarkable that to date there is no agreement on the precise anatomy of the human sympathetic nerves and in particular the variation in their trajectories relative to the renal arteries. In a small study of nine renal arteries harvested from five human autopsies, it was reported that the majority of renal nerves lie within $2 \mathrm{~mm}$ distance from the lumen of the renal artery. ${ }^{65}$ However, the fixation methodology used has been criticised and other workers have suggested that in humans, renal nerve distribution varies between the proximal-distal segments of the renal artery and that the 50th and 75th centiles of distance of nerves in the proximal segment are 2.84 and $4.67 \mathrm{~mm}$, respectively. ${ }^{66}$ Clearly, precise localisation of human renal nerves has crucial implications for the application of RDN and it is important to bear in mind that different ablation technologies (eg, RF energy, ultrasound energy, chemical ablation) offer varying depths of renal sympathectomy and it remains to be proven which is most effective for human use.

Since renal nerves spiral around the artery, it is also clear that denervation in all four quadrants of the renal artery is necessary. This may be achieved through the use of multielectrode RF ablation catheters and alternative means of sympathectomy including ultrasound and chemical ablation techniques. Ultrasound energy may offer benefit by avoiding endothelial damage and deeper penetration of heating energy than RF. Chemical ablation techniques with alcohol or guanethidine also offer potential advantage in obviating endothelial damage although it remains unclear whether or not dissemination of neurotoxin beyond the periadventitial layer could be an undesired effect of such therapy. ${ }^{18}$ Determining which energy modality and ablation therapy is best to achieve near complete renal nerve ablation in the absence of damage to the renal artery lumen (and off-target effects) remains a priority.

At present there is no marker of procedural success to inform operators that RDN therapy has been successfully delivered although in a number of studies it has been demonstrated that the higher the starting SBP, the greater the response to RDN. Preliminary data from humans indicate there could be a role for high frequency electrical field stimulation of the renal arteries. ${ }^{24}$ In a canine model, intralumenal renal artery electrical stimulation (to activate renal nerves) was shown to increase BP, serum catecholamines and heart rate variability, presumably through activation of renal afferent reflexes; these effects were attenuated following RDN. ${ }^{25}$ Currently there are no established biomarkers of renal nerve injury (a neural 'troponin' would be ideal) and early plasma markers of renal injury have not translated as trustworthy markers. Thus, interventionists remain uninformed as to whether or not the RDN procedure they have undertaken has achieved its intended purpose.

Ideally treatment with RDN would be limited to those patients most likely to respond to the therapy. If a response rate is defined as a reduction in office SBP of $10 \mathrm{~mm} \mathrm{Hg}$ or more, a number of non-randomised and non-blinded studies have indicated responder rates in excess of $80 \%$. However real world experience of RDN suggests true responder rates are much more variable 22395455 and as such it might be ideal to phenotype patients with hypertension to better predict responders/non-responders. Biochemical and ethnic phenotyping is already in place in the National Institute for Health and Care Excellence/British Hypertension Society guideline for antihypertensive pharmacotherapy where patients with low renin status (black ethnicity) are offered calcium channel blockers as first-line therapy and those with high renin status (Caucasian ethnicity) receive ACE/angiotensin receptor blocker drugs instead. ${ }^{67}$ Given the complexity of SNS signalling and how this related to changes in vasomotor tone, and the lack of easy applicable tests for large-scale determination of renal sympathetic overactivation, it seems unlikely that hypertension phenotyping for SNS upregulation will evolve into mainstream clinical practice.

Table 2 Key lessons from Symplicity HTN-3

\begin{tabular}{ll}
\hline Lesson & Recommendations for the future \\
\hline Hypertension specialists were not involved in most centres & $\begin{array}{l}\text { Routine use of multidisciplinary teams led by accredited hypertension specialist } \\
\text { Hypertension specialists should design the clinical trials in conjunction with scientists and interventionalists }\end{array}$ \\
$\begin{array}{ll}\text { Antihypertensive medications stability is critical } \\
\text { Study entry }\end{array}$ & $\begin{array}{l}\text { Stable medication regimen for at least } 8 \text { weeks prior to study entry or use of optimised medical regimen with } \\
\text { washout period of } 4 \text { weeks prior to baseline if feasible and forced titration during study (does not necessarily } \\
\text { apply to trials of RHTN) } \\
\text { Meterogeneous study population differed from prior trials of }\end{array}$ \\
$\begin{array}{l}\text { RDN with more African-Americans } \\
\text { Procedural factors }\end{array}$ & $\begin{array}{l}\text { Study subjects should reflect the population of resistant hypertensives-it is entirely appropriate to recruit all } \\
\text { ethnicities as black ethnicity is a risk factor for RHTN }\end{array}$ \\
Operator supervision & $\begin{array}{l}\text { Adequate proctoring for inexperienced operators } \\
\text { Ensure delivery of adequate ablations per artery } \\
\text { Ensure } 4 \text { quadrant delivery of ablation }\end{array}$ \\
Ossume learning curve of at least 10 procedures with each RDN system
\end{tabular}

RDN, renal denervation; RHTN, Resistant Hypertension. 
One approach that merits further study is the use of noninvasive techniques to assess baroreflex sensitivity (BRS) as impaired BRS was shown to be strongly predictive of response to RDN in patients with RHTN (although it did not predict the magnitude of BP reduction). ${ }^{23}$ RDN was found to consistently improve BRS in all patients studied regardless of heterogeneous effects on $\mathrm{BP}^{22}$ Multivariate logistic regression analysis showed lower levels of BRS to be the strongest predictor of response to RDN and independent of all other variables. ${ }^{23}$ Another small study has demonstrated a novel potential role for elevated plasma levels of angiogenic markers such as soluble fms-like tyrosine kinase-1, intercellular cell adhesion molecule-1 and vascular cell adhesion molecule- 1 as predictors of response to RDN. ${ }^{68}$

\section{CONCLUSION}

Despite the negative results from Symplicity HTN-3, it is too early to decide that RDN therapy is a failed treatment strategy for RHTN. Sufficient encouraging data for RDN as a means to treat hypertension have emerged in a number of animal models of hypertension as well as some human studies to attest to its potential as an effective treatment for at least a subsection of patients. Furthermore, studies have indicated that RDN may attenuate hypertensive heart disease, decrease arrhythmia burden and reduce arterial stiffness in addition to lowering BP. Heterogeneity in $\mathrm{BP}$ responses do suggest that $\mathrm{RDN}$ is not a treatment for all-comers with RHTN and that careful patient selection will need to be augmented by better understanding of who might best respond.

It is now the time to focus on improved study design and meticulous execution of clinical trials with careful proctoring of interventionalists who are unfamiliar with the procedure as there is undoubtedly a learning curve with all novel procedures no matter how simple they may seem from the outset. Although there is unmet need for improved treatment strategies for patients with RHTN, it is also quite possible that chronic RHTN, with all the attendant circulatory maladaptation and arterial stiffening that ensues, may not represent the best target group of patients who would derive most benefit from RDN. It remains to be proven whether or not patients with milder forms of hypertension of shorter duration could be the most appropriate population for this therapy-once again high quality clinical studies are mandated particularly as the therapy becomes less expensive in the future. Until we have better evidence of the clinical efficacy in well conducted trials the Joint UK Societies recommend continuing the moratorium on RDN in routine UK healthcare. The UK is ready to contribute to further study the place of this therapy in the management of RHTN. With the current uncertainties, it would not be reasonable to expect commissioners to meet the costs of treatment in newly designed postmarketing studies. Industry will need to meet the costs of industry-sponsored studies although we hope that commissioners will support the clinical costs of National Institute for Health Research-funded studies.

\footnotetext{
Author affiliations

${ }^{1}$ On behalf of the British Hypertension Society

${ }^{2}$ Barts NIHR Cardiovascular Biomedical Research Unit, William Harvey Research

Institute, Queen Mary University of London, London, UK

${ }^{3}$ Department of Cardiovascular Medicine, Barts Health NHS Trust, London, UK

${ }^{4}$ The British Cardiovascular Society

${ }^{5}$ The British Cardiovascular Intervention Society

${ }^{6}$ Cardiothoracic Division, The James Cook University Hospital, Middlesbrough, UK

${ }^{7}$ The British Society for Interventional Radiology

${ }^{8}$ Sheffield Vascular Institute, Sheffield Teaching Hospitals NHSFT, Northern General Hospital, Sheffield, UK

${ }^{9}$ The Renal Association

${ }^{10}$ Department of Renal Medicine, Birmingham Heartlands Hospital, Birmingham, UK
}

${ }^{11}$ The National Institute for Cardiovascular Outcomes Research, University College London, London, UK

${ }^{12}$ Interventional Radiology Unit, Gartnavel General Hospital, Glasgow, UK

${ }^{13}$ School of Physiology \& Pharmacology, Bristol Cardiovascular Medical Sciences Building, University of Bristol, Bristol, UK

${ }^{14}$ International Centre for Circulatory Health, Imperial College, London, UK

${ }^{15}$ Wessex Regional Cardiac Unit, University Hospital Southampton, UK

${ }^{16}$ Institute of Cardiovascular Sciences, University College London, London, UK

Contributors MDL conceived, designed and drafted this article, has undertaken multiple revisions of the text and takes full responsibility for this article. All other authors have reviewed and contributed to revisions of the manuscript.

Competing interests MDL is on the speaker bureau for St Jude Medical and has participated in advisory boards for St Jude Medical.

Provenance and peer review Not commissioned; internally peer reviewed.

Open Access This is an Open Access article distributed in accordance with the Creative Commons Attribution Non Commercial (CC BY-NC 4.0) license, which permits others to distribute, remix, adapt, build upon this work non-commercially, and license their derivative works on different terms, provided the original work is properly cited and the use is non-commercial. See: http://creativecommons.org/ licenses/by-nc/4.0/

\section{REFERENCES}

1 Daugherty SL, Powers JD, Magid DJ, et al. Incidence and prognosis of resistant hypertension in hypertensive patients. Circulation 2012;125:1635-42.

2 Pierdomenico SD, Lapenna D, Bucci A, et al. Cardiovascular outcome in treated hypertensive patients with responder, masked, false resistant, and true resistant hypertension. Am J Hypertens 2005;18:1422-8.

3 Persell SD. Prevalence of resistant hypertension in the United States, 2003-2008. Hypertension 2011;57:1076-80.

4 de la Sierra A, Segura J, Banegas JR, et al. Clinical features of 8295 patients with resistant hypertension classified on the basis of ambulatory blood pressure monitoring. Hypertension 2011;57:898-902.

5 Krum H, Schlaich M, Whitbourn R, et al. Catheter-based renal sympathetic denervation for resistant hypertension: a multicentre safety and proof-of-principle cohort study. Lancet 2009;373:1275-81.

6 Symplicity HTNI, Esler MD, Krum H, et al. Renal sympathetic denervation in patients with treatment-resistant hypertension (The Symplicity HTN-2 Trial): a randomised controlled trial. Lancet 2010;376:1903-9.

7 Symplicity HTNI. Catheter-based renal sympathetic denervation for resistant hypertension: durability of blood pressure reduction out to 24 months. Hypertension 2011;57:911-17.

8 Medtronic Announces U.S. Renal Denervation Pivotal Trial Fails to Meet Primary Efficacy Endpoint While Meeting Primary Safety Endpoint [press release]. 09/01/ 20142014

9 Caulfield M, de Belder M, Cleveland T, et al. The Joint UK Societies Working Group on Renal Denervation. Initial response to the Medtronic Symplicity HTN3 announcement. 2014. http://www.bhsoc.org/files/2913/9084/2931/The_Joint UK Societies_Working_Group_on_Renal_Denervation_Statement_on_Symplicity_HTN3_ pre-final.pdf

10 Bhatt DL, Kandzari DE, O'Neill WW, et al. A controlled trial of renal denervation for resistant hypertension. N Engl J Med 2014;370:1393-401.

11 Catheter-Based Renal Denervation for Resistant Hypertension: Rationale and Design of the SYMPLICITY HTN-3 Trial. 2012.

12 Savard S, Frank M, Bobrie G, et al. Eligibility for renal denervation in patients with resistant hypertension: when enthusiasm meets reality in real-life patients. I Am Coll Cardiol 2012:60:2422-4

13 Verloop WL, Vink EE, Voskuil $M$, et al. Eligibility for percutaneous renal denervation: the importance of a systematic screening. J Hypertens 2013;31:1662-8.

14 Mahfoud F, Ukena C, Schmieder RE, et al. Ambulatory blood pressure changes after renal sympathetic denervation in patients with resistant hypertension. Circulation 2013;128:132-40.

15 Ott C, Mahfoud F, Schmid A, et al. Renal denervation in moderate treatmentresistant hypertension. J Am Coll Cardiol 2013;62:1880-6.

16 Kaltenbach B, Franke J, Bertog SC, et al. Renal sympathetic denervation as second-line therapy in mild resistant hypertension: a pilot study. Catheter Cardiovasc Interv 2013:81:335-9.

17 Templin C, Jaguszewski M, Ghadri JR, et al. Vascular lesions induced by renal nerve ablation as assessed by optical coherence tomography: pre- and post-procedural comparison with the Simplicity catheter system and the EnligHTN multi-electrode renal denervation catheter. Eur Heart J 2013:34:2141-8, 8b.

18 Kapil V, Jain AK, Lobo MD. Renal sympathetic denervation-a review of applications in current practice. Intervent Cardiol Rev 2014:9:54-61.

19 Persu A, Sapoval M, Azizi M, et al. Renal artery stenosis following renal denervation: a matter of concern. J Hypertens 2014;32:2101-5. 
20 Worthley SG, Tsioufis CP, Worthley MI, et al. Safety and efficacy of a multi-electrode renal sympathetic denervation system in resistant hypertension: the EnligHTN I trial. Eur Heart J 2013;34:2132-40.

21 Fink GD, Osborn JW. Renal nerves: time for reassessment of their role in hypertension? Am J Hypertens 2014;27:1245-7.

22 Hart EC, McBryde FD, Burchell AE, et al. Translational examination of changes in baroreflex function after renal denervation in hypertensive rats and humans. Hypertension 2013:62:533-41.

23 Zuern CS, Eick C, Rizas KD, et al. Impaired cardiac baroreflex sensitivity predicts response to renal sympathetic denervation in patients with resistant hypertension. J Am Coll Cardiol 2013:62:2124-30.

24 Pokushalov E, Romanov A, Corbucci $G$, et al. A randomized comparison of pulmonary vein isolation with versus without concomitant renal artery denervation in patients with refractory symptomatic atrial fibrillation and resistant hypertension. J Am Coll Cardiol 2012;60:1163-70.

25 Chinushi $M$, Izumi $D$, lijima $K$, et al. Blood pressure and autonomic responses to electrical stimulation of the renal arterial nerves before and after ablation of the renal artery. Hypertension 2013;61:450-6.

26 Henegar JR, Zhang Y, Rama RD, et al. Catheter-based radiorefrequency renal denervation lowers blood pressure in obese hypertensive dogs. Am J Hypertens 2014;27:1285-92.

27 Linz D, Mahfoud F, Linz B, et al. Effect of obstructive respiratory events on blood pressure and renal perfusion in a pig model for sleep apnea. Am J Hypertens 2014:27:1293-300

28 Krum H, Schlaich MP, Sobotka PA, et al. Percutaneous renal denervation in patient with treatment-resistant hypertension: final 3-year report of the Symplicity HTN-1 study. Lancet 2014;383:622-9.

29 Leon MB, Kornowski R, Downey WE, et al. A blinded, randomized, placebo-controlled trial of percutaneous laser myocardial revascularization to improve angina symptoms in patients with severe coronary disease. J Am Coll Cardiol 2005;46:1812-19

30 Serruys PW. The scientific power of a "sham arm"? Eurolntervention 2014:9:1129-31.

31 Kaltenbach B, Id D, Franke JC, et al. Renal artery stenosis after renal sympathetic denervation. J Am Coll Cardiol 2012;60:2694-5.

32 Vonend 0 , Antoch G, Rump LC, et al. Secondary rise in blood pressure after renal denervation. Lancet 2012:380:778.

33 Persu A, Renkin J, Thijs $L$, et al. Renal denervation: ultima ratio or standard in treatment-resistant hypertension. Hypertension 2012;60:596-606.

34 Kapil V, Lobo MD. Clinical Considerations and the Potential for Renal Denervation. Endovascular Today [Internet] 2013; 10:[1-7 pp.]. http://evtoday.com/pdfs/et1013_ F3_Lobo.pdf

35 Persu $A$, Jin $Y$, Baelen $M$, et al. Eligibility for renal denervation: experience at 11 European expert centers. Hypertension 2014;63:1319-25.

36 Hayek SS, Abdou MH, Demoss BD, et al. Prevalence of resistant hypertension and eligibility for catheter-based renal denervation in hypertensive outpatients. Am J Hypertens 2013;26:1452-8.

37 Ezzahti M, Moelker A, Friesema EC, et al. Blood pressure and neurohormonal responses to renal nerve ablation in treatment-resistant hypertension. $J$ Hypertens 2014;32:135-41.

38 Fadl Elmula FE, Hoffmann P, Larstorp AC, et al. Adjusted drug treatment is superio to renal sympathetic denervation in patients with true treatment-resistant hypertension. Hypertension 2014;63:991-9.

39 Persu $A$, Jin Y, Azizi M, et al. Blood pressure changes after renal denervation at 10 European expert centers. J Hum Hypertens 2014;28:150-6.

40 Kandzari DE, Bhatt DL, Brar S, Devireddy CM, Esler M, Fahy M, et al. Predictors of blood pressure response in the SYMPLICITY HTN-3 trial. European Heart Journal Published Online First: 16 Nov 2014 dx.doi.org/10.1093/eurheartj/ehu441

41 Roos JC, Boer P, Koomans HA, et al. Haemodynamic and hormonal changes during acute and chronic diuretic treatment in essential hypertension. Eur J Clin Pharmacol 1981;19:107-12

42 Luscher TF, Mahfoud F. Renal nerve ablation after SYMPLICITY HTN-3: confused at the higher level? Eur Heart J 2014;35:1706-11.

43 Böhm M, Mahfoud F, Ukena C, et al. Effect of renal denervation in a real world population of patients with uncontrolled hypertension-the Global SYMPLICITY Registry. ACC Washington DC 2014; Late Breaking Clinical Trials. March 2014, DC, USA.

44 DiBona GF, Kopp UC. Neural control of renal function. Physiol Rev 1997;77:75-197.
45 Esler M. The sympathetic system and hypertension. Am J Hypertens 2000:13:99s-105s.

46 Schirmer SH, Sayed MM, Reil JC, et al. Improvements in left ventricular hypertrophy and diastolic function following renal denervation: effects beyond blood pressure and heart rate reduction. J Am Coll Cardiol 2014;63:1916-23.

47 Mahfoud F, Urban D, Teller D, et al. Effect of renal denervation on left ventricular mass and function in patients with resistant hypertension: data from a multi-centre cardiovascular magnetic resonance imaging trial. Eur Heart $\mathrm{J}$ 2014;35:2224-31.

48 Fagard $\mathrm{RH}$, Celis H, Thijs L, et al. Regression of left ventricular mass by antihypertensive treatment: a meta-analysis of randomized comparative studies. Hypertension 2009;54:1084-91.

49 Ukena C, Mahfoud F, Spies A, et al. Effects of renal sympathetic denervation on heart rate and atrioventricular conduction in patients with resistant hypertension. Int J Cardiol 2013:167:2846-51.

50 Ukena C, Mahfoud F, Linz D, et al. Potential role of renal sympathetic denervation for the treatment of cardiac arrhythmias. Eurolntervention 2013;9(Suppl R):R110-16.

51 Brandt MC, Reda S, Mahfoud F, et al. Effects of renal sympathetic denervation on arterial stiffness and central hemodynamics in patients with resistant hypertension. J Am Coll Cardiol 2012;60:1956-65.

52 Lambert GW, Hering D, Esler MD, et al. Health-related quality of life after renal denervation in patients with treatment-resistant hypertension. Hypertension 2012;60:1479-84.

53 Dorr $\mathrm{O}$, Liebetrau $\mathrm{C}$, Mollmann $\mathrm{H}$, et al. Influence of renal sympathetic denervation on quality of life. J Interv Cardiol 2013;26:536-41.

54 Chan K, Ng F, Saxena M, et al. Renal Denervation in Resistant Hypertension-a prospective case series. J Hum Hypertens 2012;26:616.

55 Dasgupta I, Taylor $\mathrm{AH}$, Watkin $\mathrm{R}$, et al. Real world experience of renal denervation in the United Kingdom-a two centre study. J Hum Hypertens 2013;27:646.

56 Caulfield M, de Belder M, Cleveland T, et al. Joint UK Societies' Consensus Summary Statement on Renal Denervation for Resistant Hypertension. 2011. http:// www.bhsoc.org/docs/Joint-UK-Societies-Summary-on-Renal-Denervation.pdf

57 Excellence $\mathrm{NIfHaC}$. Percutaneous transluminal radiofrequency sympathetic denervation of the renal artery for resistant hypertension. 2012. http://www.nice. org.uk/guidance/ipg418

58 NHS E. NHS England invites specialised services providers to take part in its innovative new programme 'Commissioning through Evaluation'. 2013. http://www. england.nhs.uk/2013/09/26/com-through-eval/

59 Schmieder RE, Redon J, Grassi G, et al. ESH position paper: renal denervation-an interventional therapy of resistant hypertension. J Hypertens 2012;30:837-41.

60 Mahfoud F, Luscher TF, Andersson B, et al. Expert consensus document from the European Society of Cardiology on catheter-based renal denervation. Eur Heart $J$ 2013;34:2149-57.

61 Moss J, Vorwerk D, Belli AM, et al. Cardiovascular and Interventional Radiologica Society of Europe (CIRSE) position statement on renal denervation for resistant hypertension. Cardiovasc Intervent Radiol 2014:37:11-12.

62 Schlaich MP, Schmieder RE, Bakris G, et al. International expert consensus statement: Percutaneous transluminal renal denervation for the treatment of resistant hypertension. J Am Coll Cardiol 2013;62:2031-45.

63 Davis $\mathrm{Ml}$, Filion $\mathrm{KB}$, Zhang $\mathrm{D}$, et al. Effectiveness of renal denervation therapy for resistant hypertension: a systematic review and meta-analysis. J Am Coll Cardiol 2013:62:231-41

64 Tomaszewski M, White $C$, Patel $P$, et al. High rates of non-adherence to antihypertensive treatment revealed by high-performance liquid chromatographytandem mass spectrometry (HP LC-MS/MS) urine analysis. Heart 2014; 100:855-61.

65 Atherton DS, Deep NL, Mendelsohn FO. Micro-anatomy of the renal sympathetic nervous system: a human postmortem histologic study. Clin Anat 2012:25:628-33

66 Sakakura K, Ladich E, Cheng Q, et al. Anatomic assessment of sympathetic peri-arterial renal nerves in man. J Am Coll Cardiol 2014;64:635-43.

67 Excellence $\mathrm{NIfHaC}$. Hypertension: Clinical management of primary hypertension in adults. 2011. http://www.nice.org.uk/guidance/cg127

68 Dorr $\mathrm{O}$, Liebetrau C, Mollmann H, et al. Soluble fms-like tyrosine kinase-1 and endothelial adhesion molecules (intercellular cell adhesion molecule-1 and vascular cell adhesion molecule-1) as predictive markers for blood pressure reduction after renal sympathetic denervation. Hypertension 2014;63:984-90. 